\title{
An Evaluation of the Crisis Counseling Offered to Garissa University Terrorist Attack Survivors, Kenya
}

\author{
Asatsa Stephen ${ }^{1^{*}}$, Rosemary Obiagaeri Ekechukwu ${ }^{2}$ \\ ${ }^{I}$ Department of Psychology, the Catholic University of Eastern Africa \\ ${ }^{2}$ Department of Educational Psychology, Guidance and Counseling Faculty of Education, University of Port \\ Harcourt Rivers State, Nigeria
}

*Corresponding Author: Asatsa Stephen, Department of Psychology, the Catholic University of Eastern Africa

\begin{abstract}
The study sought to investigate the subjective evaluation of crisis counseling that was offered to the survivors of Garissa University terrorist attack. The study was anchored on the organismic valuing theory after adversity, and adopted the phenomenological qualitative research design. A total sample of 20 participants was selected using extreme case sampling technique. Participants were screened using Posttraumatic Growth Inventory and those who scored the highest were considered for inclusion in the study. Data were collected using interview guides and analyzed using descriptive statistics, themes and narratives from participants. The study found that crisis counseling to a large extent helped participants accept the changes resulting from the terror attack, deal with denial, improve social skills, reinvest in self and process emotions. The results further showed that the crisis counseling offered to the Garissa University terrorist attack survivors had various shortcomings including not addressing family members of survivors, coping strategies and spiritual aspects arising from the attack. The crisis counseling also ignored screening, evaluation, other losses and follow up. These findings may be relevant in designing and enhancing crisis interventions for trauma survivors.
\end{abstract}

Keywords: Counseling, Trauma, Crisis, Follow up, Evaluation.

\section{BACKGROUND}

Terrorism is an emerging issue that continues to inflict psychological pain to the global population. The Institute of Economics and Peace reported that global terror attacks have increased by $450 \%$ in the last decade (Alfa, Sritharan, Mehes, Abdulla \& Rasheed, 2015). The ratio of physical to psychological casualties after terrorism attacks has been demonstrated to be very high. As noted by various global studies, critical incidents like terror have devastating psychological consequences on the survivors ranging from depression, posttraumatic stress disorder, aggressive behavior and neurobiological system problems (Terwase, Abdul-Talib, Zengeni\&Terwase, 2015) among others. The negative psychological effects of these traumatic events are not only confined to the survivors but also the general public (Maria, Jesus \& Sarah, 2016).

The burden of trauma in Africa remains high as a result of civil wars, epidemics, poverty and the emerging issue of terrorism. Ozgediz and Riviello (2008) reported that trauma accounts for the highest burden of disease in Africa yet remains neglected on the continent and less reported in international media. The rise of terror groups such as the Boko haram in Nigeria and Cameron, the Al Shabab in Somalia and neighboring countries and Islamic State in Libya and Egypt is evidence for increasing trauma on the continent. Alfa et al (2015) reported that efforts to manage mass traumatic casualties in Africa are uncoordinated as many of the affected countries lack the fundamental mental health systems to address the problem. This leaves the large traumatized population at the risk of falling into the recruitment trap of opportunistic terror groups.

The value of counseling following critical life incidents cannot be under estimated. Several studies have been conducted to evaluate the effectiveness of counseling to crisis survivors. $\mathrm{Xu}, \mathrm{Hu}$, Song, $\mathrm{Lu}$, Chen, $\mathrm{Wu}$ and Xia (2016) conducted a study examining the effect of positive psychological intervention on posttraumatic growth among primary health care workers in China. A sample of 579 health care workers from Shenzhen filled the PTGI and compared the scores with response after 
exposure to Chinese traditional psychological interventions. Correlation research design was used together with experimental approach. Pearson correlation analysis was used to analyze the data. The findings revealed that scores on PTGI were significantly higher after the psychological intervention than before. The domain of 'new possibilities' benefited most from the interventions. The current study seeks to explore the counseling implication using the qualitative approach in order to obtain rich and subjective views of the survivors since correlation coefficients alone may not bring out sufficient information about the counseling experience, which is unique to every person.

Jeon, Han, Choi, Ko and Kim (2016) also conducted a study on a sample of 10 survivors of large scale maritime disaster that occurred in South Korea. The aim of the study was to investigate the therapeutic value of Eye Movement Desensitization and Reprocessing (EMDR) on posttraumatic growth. The results indicate that after 3 months from treatment completion, significant increase in posttraumatic growth was observed. It was concluded that EMDR therapy enhanced posttraumatic growth in disaster survivors. Even though the study is one of the few that attempt to investigate the role of counseling in posttraumatic growth, the sample used was relatively lower to make a generalization. The current study focused on the overall counseling interventions used in the aftermath of adversity unlike the previous studies which focused on particular counseling models.

In the past 7 years, the number of terror attacks in Kenya increased tremendously. The global terrorism database documents over 50 related terror attacks in Kenya since 2011 (National Consortium for the Study of Terrorism and Response to Terrorism, 2017). The recent terror activities include the Westgate mall siege of September, 2013, Mandera quarry massacre of December, 2014, and the Garissa University terror attack of April, 2015. The hundreds of human life lost as a result of these attacks is a great loss, yet the resulting psychological impact would translate to thousands of people as indicated by studies (Rugiero\&Vos, 2013; Nasim\& Aziz, 2014)

The current models of psychological intervention employed in mitigating posttraumatic complications focus on psychological first aid and critical incident debriefing (Dyk\&Dyk, 2010). Critical incident debriefing is a short term strategy that largely focuses on the past negative experiences of the traumatic event. However, there is growing evidence showing that focusing clients on their current strengths and future possibilities can help foster behavioral change (Selekman, 2005). Studies conducted on traumatic events in Kenya have not explored the possible positive outcomes of trauma. The current trauma counseling models have not tapped the potential in positive outcomes of trauma and this could be attributed to the knowledge gap in this area due to sparing research.The study sought to fill this knowledge gap by evaluating the crisis counseling offered to the survivors of Garissa University terrorist attack. The aim was to identify the strengths and weaknesses of crisis counseling models in order to improve future interventions for crises.

\section{Methods}

The study was carried out at Moi University's main campus in UasinGishu County. The study adopted the phenomenological research design with participants being selected through extreme case sampling. Participants were first screened with Posttraumatic Growth Inventory (PTGI) and a sample of 20 participants who recorded the highest scores were selected for inclusion in the current study.

Following the Garissa University terrorist attack, some of the survivors were relocated to the main campus in Eldoret to continue with their studies. These are the students and staff who did not feel comfortable to continue with their studies in Garissa University, which was the place of the attack. They were integrated within the population of Moi University main campus and were proceeding with their studies at the time of this study. The unwillingness of these students to return to Garissa University could be as a result of high level of trauma experienced from the attack. These students also underwent counseling at various levels. For instance, some participants did not attend any counseling sessions at all, others attended critical incident debriefing only without follow up counseling, while others received formal counseling for various sessions up to termination level. Data were collected by interview guides and was analyzed thematically and presented in form of graphs, themes and narratives from the participants.

\section{RESUltS}

\subsection{Shortcomings of Crisis Counseling Offered to the Survivors}

The interview sought to explore the issues that counseling did not address effectively. The survivors' expectations about counseling and the counseling that was actually offered were examined with focus 
on the inconsistencies between the two situations. The responses were coded and categorized into themes as shown in figure 2 below.

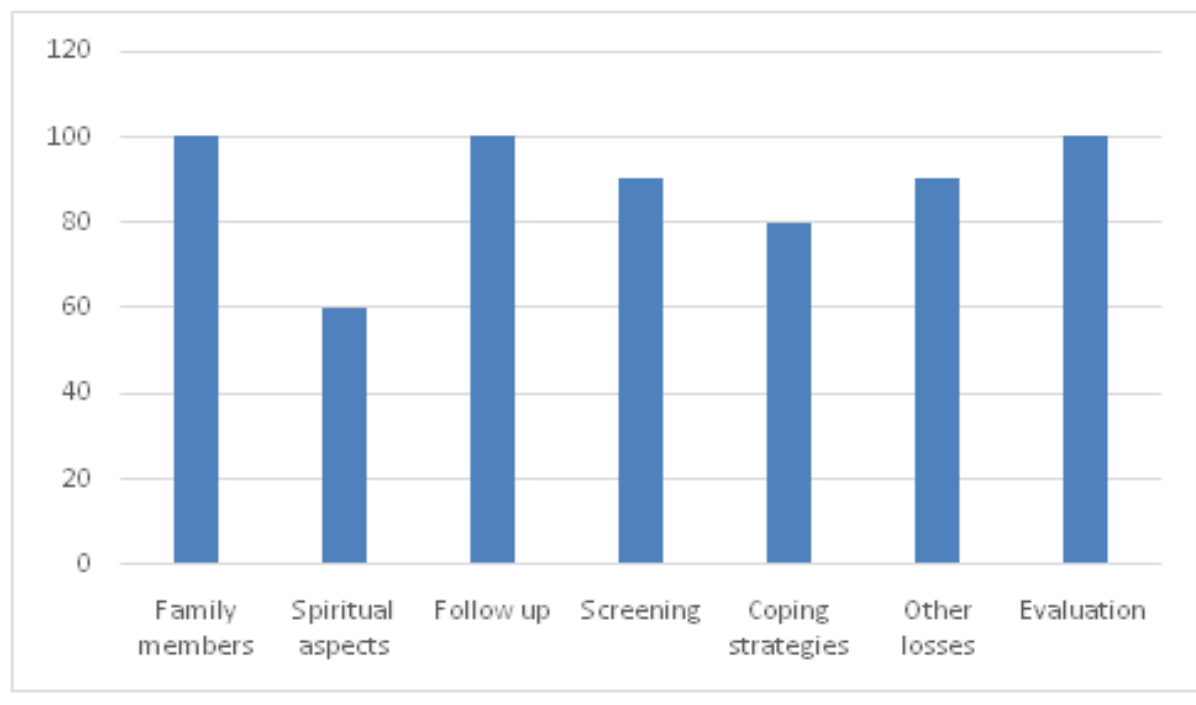

Figure1: Themes on what counseling did not address

Majority of participants indicated that the crisis counseling they received to a large extent ignored their family members $(100 \%)$, follow up (100\%) and evaluation (100\%). Others reported the lack of screening $(85 \%)$, not focusing on other losses $(85 \%)$ and coping strategies $(80 \%)$ and ignoring their spiritual aspects $(60 \%)$.

\subsection{Family Members}

It was a general concern for majority of the survivors that no attempt was made to incorporate their family members in the counseling programmes after the attack. The main focus of the counseling was the survivor as an individual. The fact that the survivors were part of a family system was ignored. The survivors reported that their significant others in the family were equally traumatized but remained disturbed due to neglect by counselors and other organizations that were involved in the rescue operation. To the survivors, seeing their traumatized parents and siblings struggling without any help was much traumatizing to them.

The survivors observed that the attack too shattered the functioning of the entire family. Parents and siblings also required help on how to live with their traumatized children but absence of this left them helpless and painful. One participant reported,

"Since the attack, my parents and siblings have changed. They became overly protective and I feel they keep surveilling me to ensure am safe. Whenever they hear of accidents or reports of any other attack in any part of the country they keep calling me to find out if am safe. If they fail to get me on the phone they go through much pain thinking I might be dead." (Participant 03, personal communication, March 1, 2018).

The survivors felt that they cannot achieve psychological wellness if their families are still living with the pain of the attack. They reported that the neglect of the entire family in the counseling process was based on the fact that the counseling was designed to end within a given period of time. Involving the family would therefore have required more time, which they felt most of the concerned organizations were avoiding. One participant said,

"I think the whole counseling process was never focused on our well-being but to finish the given work on time and get money from the donors. If they were interested in our healing process, they would not have neglected our family of origin. What was the need of being counseled to adjust to our new campus and when we go back home we see our parents still devastated? ’(Participant 02, personal communication, March 1, 2018).

\subsection{Screening}

The survivors reported that no screening was done before grouping them for counseling sessions. They felt that due to the magnitude of the attack and the coverage it was given in the media, 
counselors approached the survivors with their own assumptions about the issues they were going through. Survivors felt that the counselors were preoccupied with the terror attack to the point of not being able to capture and explore the issues that required immediate action. Little effort was made to explore the survivors' pain and priorities before help. Survivors were grouped haphazardly and taken through similar counseling as if they had same level of pain. One participant asked,

"How can you group someone who lost a laptop, who survived a gun shot, lost a friend and the one who lost a child together and take them through the same counseling process? Do these people have anything in common on the pain they went through?" (Participant 06, personal communication, March 1, 2018)

Other survivors reported that counseling was imposed on them without first exploring if they were ready to talk about the attack. For instance some survivors reported that they were pushed to attend counseling yet they felt they were not receiving any help. The reason for this was that they required time alone to process the shock before opening up to talk about it. They reported that counselors were not keen to find out the reason for their resistant to counseling but went on with counseling assuming the process was smooth. One survivor said,

"The time they brought counseling to me, I was not prepared to talk. However after some weeks, I felt I needed to share my pain with someone. I think this was the time I was ready for counseling but unfortunately, the counseling sessions had been terminated" (Participant 09, personal communication, March 2, 2018).

The crisis nature of counseling was an impediment for normal growth of clients. The survivors reported that there was a rush by counselors to help them within the shortest time possible to avoid a bigger crisis. Even though survivors desired to walk through the process with people who could understand them, counselors focused on fixing their problem. Participation of the survivors in conceptualizing their own problem was ignored. The end result was that counselors ended up addressing issues that were less important to the survivors.

\subsection{Coping Strategies}

The expectation of majority of the survivors was that counseling could help them explore on the coping strategies to handle the aftermath of the attack. Survivors reported that the attack brought new challenges that survivors had never experienced before such us intrusive thoughts about their deceased friends, hypervigilance and constant existential questions. To the surprise of many survivors, the counselors kept insisting on forgetting the pain of the attack, the deceased friends and lost items and moving on with life. They were encouraged to talk about the event and assured that if they did so, the nightmares would stop and yearning for their deceased friends would end. One participant said,

"Despite assurance from my counselor that after speaking about my friends I could forget about them, their image stuck in my mind. The night mares about their screams as they were dying remained fresh in my mind....... For me it was more painful trying to get rid of these memories than being helped on how to live with the memory." (Participant 10, personal communication, March, 2018).

The participants felt that exploring ways of living with the painful memories could have been the best approach to be used by counselors instead focusing on forgetting and moving on. Some of the cognitive functions of the survivors such as memory, decision making and rational thinking had been shaken and focus on learning new skills and to handle this new state was the desire for majority of the survivors. For those who were going through grief, counselors challenged them to release their deceased friends to the world of the dead. The survivors who still felt attached to their friends were reminded that the world of the dead and the living could not coexist and it was time to let go the deceased friends. Participants felt it was premature to let their friends go before properly mourning for the loss. One participant said,

"Two weeks was not enough for me to have finished with my deceased friends. I wanted more time to mourn, cry and remember my friends before I could let them go. I needed to know how to live with the memory of my dead friends before I could know how to let them go." (Participant 03, personal communication, March 1, 2018). 


\subsection{Follow Up}

Most participants noted that the counseling they received was an event and not a process. They reported to have felt abandoned abruptly upon the expiry of the timelines that had been set for counselling. They observed that the process started without focus on relationship building and termination occurred abruptly after which total silence between the counselors and survivors followed. Survivors recalled how counselors hurriedly took them through the counseling process, promised to make calls to follow up on the progress but ended up not following up at all. Some survivors reported struggling with disturbing dreams after termination of the counseling but lacking anyone to help them understand what was happening. One participant said,

"I think the counselors had an assignment to complete. Our healing was not their priority. The most important business they had was to finish the counseling on time and get paid. After the first month, reality of the attack really struck me but there was no counselor. Those who had taken me through the sessions were not available yet I still needed support and reassurance that all was well." (Participant 08, personal communication, March 3, 2018).

It was evident that survivors wanted longer relationship with the counselors with a gradual process of termination. They preferred to be involved in the termination process and given support beyond the stipulated counseling timelines. A few survivors who received the services of peer counselors reported very satisfactory post counseling adjustment. They felt understood by the peer counselors who were available for follow-up even after the official counseling period was over. The absence of counselors after the debriefing period was interpreted by some participants as loss. This added to the other losses they had suffered from the attack. A few of the survivors reported weakened trust after failure of the counselors to follow up as breaking of the promise of follow up through telephone was betrayal. A participant said,

"I still struggle with trust issues. The little trust I had developed during counseling was shattered by counselors who never showed interest in me upon completion of the sessions." (Participant 01, personal communication, March 2, 2018).

This was supported by the findings of Wu, He, Jiang, Zou, Liu, Zhou et al (2016) who conducted a study using a sample of 254 smoking addicts on counseling follow up. Telephone follow up was conducted from one week up to six months after termination of counseling. The findings of showed that additional follow up counseling doubled the quit rate among cigarette smokers. Follow up is not as intensive as the main counseling sessions but it appears to be vital in the change or growth process of clients and survivors of adversity. According to Corey (2009), follow up in counseling is a crucial component that can greatly enhance the outcome of counseling. Follow up helps in evaluating the effectiveness of the counseling process, the areas needed for improvement and addressing the emerging issues after termination of the counseling sessions. In the current study the desire to have had follow up sessions by the survivors could be an indication for post counseling issues that may have developed after termination.

\subsection{Other Losses}

Participants felt that counselors focused on loss as a result of death and ignored other multiple loses that they had suffered. The losses included destruction of their property, loss of time as a result of disruption of study time and loss of peace among others. To some survivors parents abandoned them and even stopped paying fees when they heard that the government and Red Cross were offering help. They perceived it as an income generating activity through donations from well-wishers. The issues that counselors focused on could were of concern to the survivors but some of the survivors felt that they had other more pressing issues to address first. One participant asked,

"How can I be counseled for psychological peace when I still had problems with paying my fees and buying food?" (Participant 08, personal communication, March 2, 2018)

The participants hoped for a holistic approach to counseling but majority of the professional counselors focused on the trauma. The causes of the trauma and perpetuating factors for the trauma were not explored at individual level. The survivors felt that some of some of their major concerns were not addressed effectively as a result of treating them as a group and not individuals with unique was of responding to crisis. For some of the participants, the terror attack was the most traumatizing 
issue, to others it was the death of their colleagues, to others it was loss of property and disruption of life routine while others it was the pain that their entire family was going through as a result of the attack. Had counselors taken enough time to explore the multiple issues at individual level and work on the problems from the clients' point of view, the survivors would have been empowered more to work on their issues. A participant reported,

"I appreciated the services of the counselors, but a large percentage of the healing I received came from my own painful struggle with the pain of going through this attack.... Am still discovering other issues of disturbance that I have not even started handling." (Participant 06, personal communication, March 1, 2018).

The psychological impact of terrorism remains among the most complex traumas to deal with since survivors experience so many losses within the same period (Ahmed \&Amer, 2012). The issues of concern for the terror survivors included their experience of the traumatic event, loss of their colleagues, destruction of their property, disruption of studies and normal routine, settling in a new environment and pain of their parents among others. As reported by most participants, the counselors' focus was the participants' experience of the terror attack and the accompanying negative emotions. It was therefore evident that counseling of the survivors was terminated with many unfinished issues that probably seemed not important to the counselors yet vital to the participants. This could also justify why participants felt that screening should have been done to identify their priorities in the issues addressed during the counseling process.

\subsection{Spiritual Issues}

Some participants believed that counseling did not focus on the spiritual aspects of their life. The attack raised many existential questions that could not be answered. The survivors had seen their colleagues executed as a result of their faith and to some their own faith was shaken. Survivors doubted the saving power of God, since some of their devout friends had been murdered while in prayer. The death had initiated intrapersonal debate of whether or not God was real. As survivors kept asking this questions, at personal level they had felt God had saved them from the attackers. This bipolar experience with God left them more confused on matters of faith. This confusion was either ignored by counselors or addressed using cognitive approaches which did not make sense to the survivors. Majority of participants believed in life after death and hoped to meet the deceased colleagues some day in the future. However some counselors confronted this by encouraging the survivors to disengage with the dead. One participant reported,

"My local church really helped me sort out my confusion about God. With my pastor we got examples from the Holy Scriptures of people who had gone through worse experiences. Some of my questions were answered. Through prayer I let God know my pain and how I felt abandoned by him. My healing started here." (Participant 10, personal communication, March 3, 2018).

Participants who did not connect with their spiritual leaders felt they still had a number of spiritual issues that were not addressed effectively by the counseling process. Some participants felt they needed prayer before and after counseling but the kind of counseling offered did not offer such an opportunity. They believed the counselors should have worked in partnership with God in order to find answers to the difficult questions they had. Others who were not committed to God before the attack developed great zeal for God but they felt no one was there to help them actualize this decision.

\subsection{Evaluation}

Majority of the participants reported that they were not given time to evaluate the process and sessions. They felt the entire process had solely depended on the counselors and not them. For instance the decision on when to start counseling, when to terminate and how the survivors were responding to the counseling were all left to be interpreted and decided by the counselors. Participants felt that the help they received from counseling could have been maximized if regular evaluation of the process was done to get their views and give feedback on the relationship. One participant said,

"I believe some of my key issues in relation to the attack were never addressed because the counselors did not take time to find out how their sessions were impacting on me. "(Participant 04, personal communication, March 3, 2018). 
The participants envisioned a comprehensive and regular evaluation process as part of the counseling process but the counselors, bound by time factor, rushed in carrying out the entire process as a crisis.

\section{DISCUSSION}

It was reported that majority of the counselors were focused on emotion processing and the survivors who had blocked emotions and found a way of venting them out. This finding agrees with Vanhooren, Leijssen and Dezutter (2018) who reported that emotional support was positively correlated with posttraumatic growth among incarcerated individuals. Calhoun and Tedeschi (2013) described counseling as expert companionship which help trauma survivors to process their painful emotions and develop new ways of thinking. The focus of counselors on emotional issues of participants was therefore crucial to healing and functioning beyond the pre-trauma levels. According to Alayarian (2011), emotional blockage can be one way of storing trauma in the body and liberation from this could mark the beginning of progress in trauma treatment. The presence of emotional blockage among the participants, could have been an impediment to their cognitive processes which are vital in posttraumatic growth.

According to Barrington and Shakespeare-Finch (2013) reinvesting in self after trauma helps survivors to return to normalcy. Traumatic events cause major disruption in life and alter normal routines in the life of survivors. These disruptions may further intensify trauma as they constitute loss. In the current study, the focus of counselors on re-investing in self among survivors was a key step towards trauma recovery. The challenge towards reorganization of life after trauma among these survivors could have boosted self-introspection hence finding meaning. According to terror management theory reinvesting in self may take the form of beginning projects that may outlive the concerned person as a way of reducing death anxiety (Solomon, Greenberg \&Pyszczynki, 2015). From the testimonies of participants in the current study, it is clear that some of participants decided on investing in self as a way of defeating the awareness of death.

Calhoun and Tedeschi (2013) referring to counseling in posttraumatic growth as expert companion imply that counseling is a relationship built on trust and empathy. By virtue of the process of counseling being a relationship, development of social skills among the survivors would be inevitable. The findings of Vanhooren, Leijssen, Dezutter(2017) agree with the current study on the development of interpersonal skills through counseling. In their study which used qualitative research design participants reported to have improved in the way they related with others. Among the social skills reported by the participants included improved empathy, perceiving others differently, being authentic in relationships, and improved self- disclosure

Counseling was instrumental in helping the survivors process the denial. Other participants reported pain during the denial stage. They felt that failing to accept the death of their friends was the most painful experience as it disrupted their sleeping patterns and general life routines. This is consistent with the findings of Barbara (2013) who asserted that counseling was instrumental in reducing denial among children with sexual behaviour problems. Freda (2014) reported similar findings confirming the role of counseling in processing of negative coping mechanisms among trauma survivors. The current study found that negative cognitive processing strategies namely denial and regret were negatively predicted posttraumatic growth. The role played by counseling in reducing denial could therefore have paved way for enhancement of posttraumatic growth among the participants.

Studies have shown that the reduction of denial and other negative coping mechanisms after counseling automatically pave way for acceptance and other positive trauma coping strategies (Freda, 2014; Barbara, 2013). In the current study participants accepted the reality of the terrorist attack despite the pain associated with it. McHugh, Forbes, Bates, Hopwood \& Creamer (2012) found that psychotherapy helped survivors of trauma in development of gratitude and forgiveness, virtues that are important in letting go the past and embracing growth.

This study has demonstrated that terrorism is a psychological war aimed at hurting or killing a few people to devastate many. Lopez and Pineda (2011) reported that in Oklahoma City bombing in 1995, there were 168 fatalities but over 8000 individuals sought crisis intervention. This argument was supported by the findings of Nasim and Aziz (2014) who conducted a survey on the effects of terrorism in Pakistan and reported 3.9\% physical effects, $17.2 \%$ social effects and $79.2 \%$ mental health effects. This trend demonstrates that with the 148 deaths of the Garissa University terrorist 
attack, thousands of other people could have been traumatized through vicarious trauma. Among those affected could be the relatives of the deceased and survivors, the aid workers and security forces involved in the rescue operation, the general public who received the news of the attack through mass media and friends of the survivors who continue to hear the narration of the survivors about the attack. Focusing counseling services on the students who survived the attack alone therefore left out a large percentage of traumatized people who continue to suffer in silence.

As indicated by respondents in the current study, leaving out family members of the survivors during counseling was a serious flaw that left many psychological wounds unattended. It is also possible that this neglect may continue to serve as secondary trauma to the already traumatized survivors. It is not possible to sustain the trauma healing achieved during counseling when the images of traumatized parents and relatives continue to be witnessed whenever the survivors go back home. The researcher was aware that the focus of counseling of the trauma survivors to the victims alone could have been a product of many other factors ranging from inadequate finance in the implementing organizations and limited number of trained professional counselors to serve the general public. However it is also important to note that expanding the counseling network to capture the close relatives of the survivors and the deceased could have improved the long term outcomes of the counseling process at relatively lower cost.

According to Mustaffa, Afsaneh and Ahmad (2013), assessment is an essential part of the counseling process which acts as a guide to making decisions about which intervention strategies to use. With the absence of proper screening approaches for the population in the current study, chances of having used wrong interventions could be high. Bray (2010) asserts that successful treatment plan in psychotherapy depends on the nature of assessment of the problem done.The decision not to do screening for the survivors of Garissa University terror attack could have been informed by the nature of publicity the event received in the local and international media.It could be possible that most counselors attended to the survivors basing on the information they received through the press and neglected the subjective feelings of the individual survivors. This could be justified by the numerous issues that participants listed as part of what counselors failed to address in their struggle with trauma.

The exploration of coping strategies after trauma experience has been supported by the findings of Oginska and Zadworna (2018) who reported that avoidance strategies played a greater role in posttraumatic growth than strategies focusing on the problem. The study used a sample of 80 emergency medical workers with quantitative approach. Similar findings were reported by Oginska and Kobylarczyk (2017) who found that seeking social support and other coping strategies enabled people who had experienced trauma to adapt to the situation and development of posttraumatic growth. The urge of the participants to be given coping strategies also implied that counselors could have relied heavily on exploration of the past at the expense of examining future possibilities for the survivors. There was need to diversify the counseling techniques for trauma survivors to include cognitive approaches that focus on teaching new competencies and skills.

This is consistent with the findings of Vanhooren, Leijssen, Dezutter, (2017) who found significant mean differences between those who received help from a chaplain and those who did not. The study reported that trauma survivors who received chaplaincy services recorded higher posttraumatic growth levels compared to those who did not. The findings of Shaw, Joseph, Linley(2007) showed that religion and spirituality were beneficial to people in the aftermath of trauma. The study established that traumatic experience led to deepening of religiosity and spirituality. In the current study, participants to a large extent felt the lack of spiritual approach in the counseling offered. This could imply that most of the existential questions that might have emerged after the terrorist attack remained unanswered after termination of counseling. According to the organismic valuing theory, organismic valuing process begins, where existential questions are asked with the aim of seeking for meaning to understand the significance of the traumatic event (Joseph \& Linley, 2005). Meaning searching may lead to either negative accommodation through reactions of hopelessness, helplessness and pain; or positive accommodation through improved relationships, change of personal philosophy and change of self-view. Religion and spirituality are known to create hope, meaning and initiate review of life philosophy (Triplett, Tedeschi, Cann, Calhoun, Reeve, 2012). As reported by the participants in the current study, exploration of spirituality and religious dimension of the survivors could have to a large extent led to better resolution of trauma and enhanced posttraumatic growth through processing of existential difficulties. 
The finding of See and $\mathrm{Ng}$ (2010) highlighted on the importance of evaluation in counseling which agreed with the findings of the current study. This was supported by Jaladin (2011) who found that evaluating counseling outcomes was a key component of counseling. Evaluation of the counseling process is a feedback exercise that could allow the consumers of counseling services to rate the quality of services received. In the current study participants were not exposed to this and most of them felt left with important information that could have assisted the counselors in offering better services in future. The issues raised by participants in the current study on the quality of counseling services received after the terrorist attack point at serious gaps in the training, recruitment and supervision of counselors that should be areas of focus by the various professional counseling bodies in the country in order to minimize harm to clients.

\section{CONCLUSION}

The study findings showed that crisis counseling after the Garissa University terrorist attack assisted the survivors stabilize psychologically. However from the findings of this study, it is important to note that the issues raised by participants as short comings of the crisis counseling require attention. The issues present evidence that survivors required specialized and trauma- tailored counseling to fully address their concerns yet the counseling that was offered was more general. The lack of screening and follow up showed that the crisis counseling was rushed and offered as an emergency. Future crisis interventions may consider designing counseling strategies that are more client centered, trauma focused, family focused and holistic to the survivors targeting the physical, spiritual and emotional dimensions. Multi agency approach and collaboration with other helping professions could help in addressing the needs of survivors holistically which would improve the quality of crisis counseling.

\section{REFERENCES}

[1] Ahmed, S. \&Amer, M. M. (Eds.). (2012). Muslim mental health. Florence, KY: Routledge.

[2] Alayarian, A. (2011). Trauma torture and dissociation: A psychoanalytic view. London, GBR: Karnac Books.

[3] Alfa, M. Sritharan, K., Mehes, M., Abdulla, I., Rasheed, S. (2015).Terrorism Related Trauma in Africa, and Increasing Problem. Journal of Epidemiology and Global Health, 2015 (5) 201-203.

[4] Barbara R. (2013). Denying Denial in Children with Sexual Behavior Problems. Journal of Child Sexual Abuse 22:1, pages 32-51.

[5] Barrington, A. J. \& Shakespeare-Finch, J. (2013). Working with refugee survivors of torture and trauma: An opportunity for vicarious post-traumatic growth. Counselling Psychology Quarterly, 26(1), 89-105. doi:10.1080/09515070.2012.727553.

[6] Bray, J. H. (2010). Couple and family assessment. The Wiley-Blackwell Handbook of Family Psychology, 151-164.

[7] Calhoun, L. G., \&Tedeschi, R. G. (2013). Posttraumatic growth in clinical practice. New York, NY: Routledge.

[8] Corey, G. (2009). Theory and practice of counseling and psychotherapy. Belmont, CA: Thomson Brooks/Cole.

[9] Dyk, V. E., \&Dyk, V. G. (2010). Psychological Debriefing of Trauma: A proposed Model for Africa. Trauma Debriefing, 6(2) 379- 394.

[10] Freda B. (2014). Child sexual abuse in early-childhood care and education settings. Early Child Development and Care 184:9-10 1415-1435.

[11] Jaladin, M. A. R. (2011). How to Successfully Engage with Culture and Diversity Issues in a Cross Cultural Counseling Process: From Research to better Practice (Unpublished Doctoral Dissertation). Monash University, Melbourne, Victoria Australia.

[12] Jeon, S. W., Han, C., Chi, J., Ko, Y. H., \& Kim, Y. K. (2016). Eye Movement Desensitization and Reprocessing to Facilitate Posttraumatic Growth: A prospective Clinical Pilot Study on Ferry Disaster Survivors. ClinPsychopharmacolNeurosci, 15 (4) 320-327.

[13] Joseph, S., \&Linely, A. P. (2005). Positive Adjustment to Threatening Events: An Organismic Valuing Theory of Growth through Adversity. Review of General Psychology, 9 (3) 262- 280. Doi: 10. 1037/10892680.9.3.262.

[14] Lopez, L.W \& Pineda, C. (2011). Terrorism: Two Complementary Approaches. TerapiaPsicologica, 29 (2) $225-231$.

[15] Maria, P. G., Jesus, S., \& Sarah, G. (2016). A systematic Review of the Literature on Posttraumatic Stress Disorder in Victims of Terrorist Attacks. Psychological reports, 119 (1) 328-359. 
[16] McHugh, T., Forbes, D., Bates, G., Hopwood, M., \& Creamer, M. (2012). Anger in PTSD: Is there a need for a concept of PTSD-related posttraumatic anger? Clinical Psychology Review, 32, 93-104.

[17] Mustaffa, S., Afsaneh, G. \& Ahmed, R. (2013). Assessment in Family Counseling. Predocia Social and Behavioral Sciences, 93 (2013) 2205-2205.

[18] Nasim, S., Khan, M. \& Aziz, S. (2014). Impact of Terrorism on Health and Hospital Anxiety Depression Scale Screening in Medical Students in Karanchi, Pakistan. J Pak Med Assoc, 64 (3) 275-280.

[19] National Consortium for the Study of Terrorism and Response to Terrorism (2017). Global Terrorism Database. Retrieved from http: www.start.umd.edu/gtd?

[20] Oginska, B. N \&Kobylarczyk, M. (2017). The Experience of Trauma Resulting from the Loss of a Child and Posttraumatic Growth. The Mediating Role of Coping Strategies, Class of a child, Posttraumatic Growth and Coping. Omega Journal of Death and Dying, 0 (0) 1- 6.

[21] Oginska, B. N. \&Zadworna, C. M. (2018). The rise of resiliency and coping strategies in occurrence of positive changes in Medical rescue workers. International Emergency Nursing, 18 30018-1. Doi: 10.1016/j.ienj.02.004.

[22] Ozgediz, D., Riviello, R. (2008). The other neglected diseases in global public health: Surgical Conditions in Sub-Saharan Africa. PLOS Med 2008 (5) el 121.

[23] Ruggiero, A \&Vos, M. (2013). Terrorism Communication: Characteristics and Emerging Perspectives in Scientific Literature 2002 - 2011. Journal of Contingencies and Crisis Management, 21 (3) 153-166.

[24] See, C. M., \& Ng, K. M. (2010). Counseling in Malaysia: History, Current Status, and Future Trends. Journal of Counseling \& Development, 88(1), 18-22.

[25] Selekman, M (2005). Pathways to change: Brief therapy solutions with difficult adolescents (2nd ed.). New York: Guilford Press.

[26] Solomon, S., Greenberg, J. \&Pyszczynski, T. (2015). The worm at the core: The role of death in life. New York: Random House.

[27] Terwase, F., Abdul-Talib, A., Zengeni, T. K., \&Terwase, M.C. (2015). Psychological Trauma on Boko Haram Victims in Nigeria: Conflict Resolution Perspective. Mediterranean Journal of Social Sciences, 6 (6) 519-525.

[28] Triplett, K. N., Tedeschi, R. G., Cann, A., Calhoun, L. G., \& Reeve, C. L. (2012). Posttraumatic growth, meaning in life, and life satisfaction in response to trauma. Psychological Trauma: Theory, Research, Practice, and Policy, 4, 400-410. Doi: 10.1037/a0024204.

[29] Vanhooren, S. , Leijssen, M. , \&Dezutter , J . (2018). Coping Strategies and Posttraumatic Growth in Prisons. The Prison Journal, 98 (2) 123-142. Doi: 10.1177/0032885517753151.

[30] Vanhooren , S. , Leijssen , M. , \&Dezutter , J . (2017, February 9). Ten Prisoners on a Search for Meaning: A Qualitative Study of Loss and Growth During Incarceration. The Humanistic Psychologist. Advance online publication. http://dx.doi .or g/10.103 7/h um0000055.

[31] Xu, X., Hu, M. L., Song, Y., Lu, Z. X., Chen, Y. Q., Wu, D. X \& Xia, T. (2016). Effect of Positive Psychological Intervention on Posttraumatic Growth among Primary Health Care Workers in China: A preliminary Prospective Study. Scientific reports, 2016 (6) 39189.

Citation: Asatsa Stephen, Rosemary Obiagaeri Ekechukwu. "An Evaluation of the Crisis Counseling Offered to Garissa University Terrorist Attack Survivors, Kenya. "International Journal of Humanities Social Sciences and Education (IJHSSE), vol 5, no. 8, 2018, pp. 119-128. doi: http://dx.doi.org/10.20431/2349-0381.0508014.

Copyright: (c) 2018 Authors. This is an open-access article distributed under the terms of the Creative Commons Attribution License, which permits unrestricted use, distribution, and reproduction in any medium, provided the original author and source are credited. 